\title{
Viral Esophagitis
}

National Cancer Institute

\section{Source}

National Cancer Institute. Viral Esophagitis. NCI Thesaurus. Code C27108.

Viral infection of the esophagus. It often occurs in immunocompromised patients and it is caused by cytomegalovirus or herpes simplex virus. Symptoms include pain on swallowing, fever, and retrosternal burning. 